\title{
Comparing dietary practices and nutritional status of children on school feeding programme with others in Jos North Local Government Area, Plateau state
}

\author{
Banwat $\mathrm{ME}^{1}$, Fayenuwo $\mathrm{JO}^{2}$, Pamtok $\mathrm{AO}^{2}$, Okorie $\mathrm{CJ}^{2}$, Okoro $\mathrm{L}^{2}$, Tagurum $\mathrm{YO}^{1}$, Akosu $\mathrm{TJ}^{1}$, Chingle \\ $\mathrm{MP}^{1}$ and Zoakah $\mathrm{AI}^{1}$ \\ ${ }^{1}$ Department of Community Medicine, College of Health Sciences, University of Jos, Jos. \\ ${ }^{2}$ Department of Community Medicine, Jos University Teaching Hospital, Jos \\ Correspondence: Banwat ME. e-mail: mathildabanwat@yahoo.com Phone:+234 8036133983
}

\begin{abstract}
Background: Childhood malnutrition is a public health problem in most developing countries and in Nigeria, to control it the school feeding programme was launched. This study sought to compare dietary practices and nutritional status of school children on the feeding programme with those not included in the programme, in Jos North Local Government Area, North-Central Nigeria.

Methods: This school-based comparative cross-sectional study was carried out among 247 pupils selected using a two-staged sampling technique from four public primary schools; two of which were running the National School Feeding Programme. Data was collected and analysed using Statistical Package for Social Sciences version 21.0. A 95\% confidence interval was used and a probability value of $p \leq 0.05$ was considered statistically significant.

Results: There was no statistically significant difference in the nutritional practices of the pupils in both groups $(p=0.3661)$ and majority of the pupils on the school feeding programme liked the food served because it was palatable. The prevalence of stunting among school-fed pupils was $43.3 \%$ compared with $47.5 \%$ among the nonschool fed pupils $(p=0.035)$. The prevalence of overweight among school-fed pupils was $1.6 \%$ compared with $2.5 \%$ among those not on the school feeding programme ( $p=0.456)$. The proportion of children with normal weight for height was higher among school-fed pupils (92.1\%) compared with the non-school feeding programme group (84.2\%) $(p=0.035)$.
\end{abstract}

Conclusion: There was no difference in the dietary practices reported by both groups of pupils; however, nutritional status was better among the school-fed children. It is recommended that the school feeding programme be extended to all public primary schools in Jos North $L G A$.

Key words: School-children, Anthropometry, Nutrition, Status

\section{Introduction}

Childhood is an important stage for both physical and mental development of the child. It is characterized by extreme physical changes including increase in height, bone and muscle growth. This period is also associated with active participation in sports and exercises, resulting in increased demand for energy and nutrients. ' Nutrient requirement during childhood is at their highest for many nutrients. A suitable diet for children 
should therefore ensure that all nutrient requirements are met in order to protect current and future health in addition to being palatable.

A child becomes malnourished because of illness in combination with inadequate food intake. Insufficient access to food, poor health services, the lack of safe water and sanitation, and inadequate child and maternal care are underlying causes of childhood malnutrition. ${ }^{2}$ Among the poor, there is often not enough food at home, and most schools in developing countries do not have a canteen or cafeteria. While on an empty stomach, children become easily distracted and have problems concentrating on their school lessons. ${ }^{3}$

Childhood malnutrition is a public health problem in most developing countries with adverse consequences on the socioeconomic development of nations. Globally, it is estimated that there are nearly 20 million children who are severely and acutely malnourished with most of them living in south Asia and subSaharan Africa. ${ }^{4}$ The worldwide malnutrition estimation rates indicate that $35.8 \%$ of preschool children in developing countries are underweight, $42.7 \%$ stunted and $9.2 \%$ wasted. $^{5}$ Globally, in the year 2012, a quarter of children under five years were stunted with $15 \%$ underweight, $8 \%$ wasted and $6 \%$ overweight. ${ }^{1}$ Prevalence of overweight in sub-Saharan Africa is the same as the global situation in school aged children, however, there are higher levels of stunting $(37 \%)$, underweight $(21 \%)$ and wasting $(9 \%)$ in Africa than in other regions of the world. ${ }^{6}$ In Plateau State, 2013 estimates showed that five of every 10 children were malnourished, $43.7 \%$ stunted, $18.1 \%$ underweight and $4.6 \%$ wasted.

In 2005, the Federal Government of
Nigeria launched the School Feeding Programme (SFP) with the assistance of the United Nations' Children Fund (UNICEF) and the New Partnership for Africa's Development (NEPAD) ${ }^{8}$ The SFP is an organized programme that alleviates hunger while supporting education, health and community development. ${ }^{9}$ It is defined by interventions that deliver a meal or snack to children in the school setting with the intent of improving attendance, enrolment, nutritional status and learning outcomes. ${ }^{10}$ School feeding can be provided as meals or snacks to be eaten during school hours or distributed as dry take home food rations to pupils at the end of each day, month or school term, if they attended school regularly. ${ }^{11}$ It is a versatile preventive measure that is used as a platform to support children and their families in a variety of contexts.

School Feeding Programme has been adopted in many countries throughout the world to fight short-term hunger by ensuring at least one daily nutritious meal is given to school aged children. It also supports access to education by ensuring the attendance of pupils in school. ${ }^{8}$ Studies on the impact of school feeding programmes have shown varied outcomes. ${ }^{1}$ For instance, its impact on school enrolment and attendance has been conclusively positive. However, studies on the superior dietary quality of school meals and its effect on academic achievement of school-aged children receiving school meals compared to non-school-fed children have not shown any statistically significant association. ${ }^{1}$ There is a dearth of studies that compare the anthropometry of children on the SFP and those not on the programme, necessitating the need for this study. Furthermore, the present high level of household and national food insecurity in the country, a significant increase in the incidence of malnutrition and the 
persistent insecurity in present day Nigeria, justify the need for this study. This study sought to compare the dietary practices and nutritional status (using anthropometric measurements) of pupils in public primary schools on the SFP and those not on the feeding programme in Jos North LGA, Plateau State.

\section{Methods}

This study was a school-based comparative cross-sectional study involving pupils attending public primary schools in Jos North LGA. Jos North LGA is one of the seventeen LGA in Plateau State with a land mass of $291 \mathrm{~km}^{2}$. Jos North LGA has an estimated total population of 429,300 with most of the population in the middle and lower social classes. ${ }^{12}$ There are 37 public schools on the SFP and eight non-SFP public schools in the LGA. The SFP had been on in those schools for over a year at the time of the study.

Study population comprised public school pupils in primary 1-6 in Jos North LGA registered in the school for at least one academic year whose parents or guardians consented to the study by returning signed consent forms to the researchers. The pupils were interviewed in the presence of their teachers after which their anthropometric measurements (height and weight) were taken. Minimum sample size of 247 was determined using appropriate formula for prevalence study and a prevalence of $18.1 \%$ (regional prevalence of under nutrition in Jos). ${ }^{7,13}$ Respondents for the study were selected using a twostaged sampling technique. In the first stage, sampling frame of lists of SFP primary schools (37) and another for nonSFP primary schools (8) in Jos North LGA was gotten. Simple random sampling technique was used to select two schools each from each group using table of random numbers. In the second stage, the sampling frame was gotten from the school attendance register. The minimum sample size was divided by four (4) to get the minimum number of pupils to be sampled from each school (62 pupils). From each school, 10 pupils each were selected from primaries $1-5$, while 12 were selected from primary six. Depending on the number of arms in each school, the number was subdivided to get representatives from each arm; five each for classes $1 \mathrm{a}$ and $1 \mathrm{~b}$ or 3:3:4 for classes $1 \mathrm{a}, 1 \mathrm{~b}$ and $1 \mathrm{c}$ respectively. For each arm, systematic sampling technique was used to select the pupils. The sampling interval $(\mathrm{k})$ was gotten by dividing the sampling frame (number of students in the attendance register) by the desired sample size for the arm (four or five depending on the number of arms in the school). The first pupil was selected using simple random sampling by balloting; after that every $\mathrm{k}^{\text {th }}$ child was then sampled. A total of 120 pupils were sampled from the SFP group while 127 were sampled for the non-SFP group.

The questionnaire used for data collection was interviewer administered and contained three sections. Section A assessed the socio-demographic characteristics of parent and pupil, section $\mathrm{B}$ recorded data regarding their dietary practices, while section $\mathrm{C}$ contained the nutritional status of the pupil. It was pretested on 25 pupils in a private primary school in Jos North LGA and appropriate changes made before the study. The pupils were weighed wearing only school uniforms and without shoes. A Camry weighing scale was used. Each pupil was made to stand on the scale without holding onto any support with feet apposed, hands by the sides and head in a forward position. Weight was read twice and the average taken and recorded to the nearest $0.1 \mathrm{~kg}$. Each pupil's height was measured with a 
well mounted stadiometer. Two measurements were taken and the average was recorded to the nearest $0.1 \mathrm{~cm}$. Before height measurements, pupils were asked to take off all foot wears and head gears or hats if any. Each pupil was made to stand with back against a pole of the stadiometer, heels together and in line with the buttocks, shoulders and head. With a horizontal line of sight to the respondent, the head piece of the stadiometer was used to ensure that the top of the head was measured at right angle to the stadiometer.

Statistical Package for Social Sciences (SPSS) version 21.0 was used for data analysis. Anthropometric measurements were termed "normal" between -2 and +2 Z-scores. A 95\% confidence interval was used and a probability value of $p \leq 0.05$ was considered statistically significant. Ethical approval for the study was obtained from the Jos University Teaching Hospital (JUTH) Health Research Ethical Committee. Written approval for the study was obtained from the local government's education unit as well as the head-teachers in each of the selected schools. Each pupil took a consent form home to his/her parents to obtain written permission to be included in the study.

\section{Results}

Out of the 247 pupils studied, $48.6 \%$ were from schools not implementing SFP. The ages of the pupils ranged between 5-16 years in both groups. The proportion of females was less in the SFP implementing group $(48.3 \%)$ than the non-SFP group $(56.7 \%)$. (Table 1$)$. Table 2 shows that majority of the pupils $(89.0 \%)$ reported that palatability of the food was what they liked most and only a few students (13.4\%) expressed their dislike for the food served, with $6.3 \%$ mentioning the spicy nature of the food as the reason for their dislike. Using their intake of vital meals of breakfast and dinner as a pointer to their dietary practices, it was found that most of the pupils in both groups usually ate breakfast at home before going to school (98.4\% for pupils in the SFP group and $96.2 \%$ for non-SFP pupils). There was no statistically significant difference between the two groups regarding their frequency in eating vital meals of breakfast and dinner $(\mathrm{p}=0.3166)$. (Table 3$)$

The prevalence of overweight among SFP pupils was $1.6 \%$ compared with $2.5 \%$ among non-SFP pupils. The proportion of pupils with normal weight was slightly higher in the SFP group (78.7\%) compared with the non-SFP group (77.5\%). There was no statistically significant difference in the prevalence of overweight between the two groups $(p=0.456)$. (Table 4$)$. The prevalence of stunting among SFP pupils was $43.3 \%$ compared with $47.5 \%$ among non-SFP pupils and this difference was statistically significant $(\mathrm{p}=0.035)$. (Table 4). The proportion of children with normal weight for height was higher in the SFP $(92.1 \%)$ than non-SFP group (84.2\%) and this difference was statistically significant $(p=0.035) .($ Table 4$)$ 
TABLE 1: Socio-demographic characteristics of pupils on SFP and non-SFP

\begin{tabular}{lcccc}
\hline Variable & $\begin{array}{c}\text { SFP Group } \\
\mathbf{n}=\mathbf{1 2 7} \\
\text { Freq. (\%) }\end{array}$ & $\begin{array}{c}\text { Non -SFP Group } \\
\mathbf{n}=\mathbf{1 2 0} \\
\text { Freq. (\%) }\end{array}$ & $\chi^{2}$ & P-value \\
\hline Age group (years) & & & & \\
$5-7$ & $23(18.1)$ & $34(28.3)$ & & $0.2215^{*}$ \\
$8-10$ & $82(64.4)$ & $64(53.3)$ & & \\
$11-13$ & $19(15.0)$ & $20(16.7)$ & & \\
$14-16$ & $32.3)$ & $2(1.7)$ & & \\
Sex & & & & \\
Males & $55(43.3)$ & $62(51.7)$ & 4.737 & 0.2352 \\
Females & $72(56.7)$ & $58(48.3)$ & & \\
Religion & & & & \\
Christian & $102(80.3)$ & $112(93.3)$ & 2.592 & 0.8203 \\
Muslim & $25(19.7)$ & $8(6.7)$ & & \\
\hline
\end{tabular}

Fisher's Exact Test*

TABLE 2: Perception of SFP food by pupils in SFP group $(n=127)$

\begin{tabular}{lr}
\hline Variable & Freq. (\%) \\
\hline Most liked thing about the food & \\
It is sweet & $113(89.0)$ \\
Combination of re asons & $6(4.7)$ \\
Its quantity satisfies me & $5(3.9)$ \\
It makes me grow & $2(1.6)$ \\
Variety of dishes & $1(0.8)$ \\
Most disli ked thing about the food & \\
Nothing & $110(86.6)$ \\
Too spicy & $8(6.3)$ \\
Types of food items cooked & $7(5.5)$ \\
Quantity is too small & $2(1.6)$ \\
\hline
\end{tabular}

TABLE 3: Comparison of nutritional practices of pupils on SFP and non-SFP

\begin{tabular}{|c|c|c|c|c|c|}
\hline & \multicolumn{2}{|c|}{$\begin{array}{c}\text { School Fed } \\
n=127\end{array}$} & \multicolumn{2}{|c|}{$\begin{array}{c}\text { Not School F ed } \\
n=120\end{array}$} & \multirow[b]{2}{*}{ p -value } \\
\hline & $\begin{array}{l}\text { Freq. }(\%) \\
\text { Yes }\end{array}$ & $\begin{array}{l}\text { Freq. (\%) } \\
\text { No }\end{array}$ & $\begin{array}{l}\text { Freq. }(\%) \\
\text { Yes }\end{array}$ & $\begin{array}{l}\text { Freq. (\%) } \\
\text { No }\end{array}$ & \\
\hline $\begin{array}{l}\text { Eat breakfast } \\
\text { usually }\end{array}$ & $125(98.4)$ & $2(1.6)$ & $116(96.2)$ & $4(3.8)$ & $0.3372 *$ \\
\hline \multicolumn{6}{|l|}{ Weekly intake } \\
\hline Daily & $116(91.3)$ & & $99(82.5)$ & & $0.3166^{*}$ \\
\hline 1-3 days/week & $4(3.1)$ & & $10(8.3)$ & & \\
\hline 4-6 days/week & $5(3.4)$ & & $8(6.7)$ & & \\
\hline Never & $2(1.6)$ & & $3(2.5)$ & & \\
\hline
\end{tabular}

*Chi-Square 
TABLE 4: Comparison of nutritional status of pupils on SFP and non-SFP

\begin{tabular}{|c|c|c|c|c|}
\hline Variable & $\begin{array}{c}\text { School Fed } \\
\mathbf{n}=127 \\
\text { Freq. }(\%)\end{array}$ & $\begin{array}{l}\text { Not School Fed } \\
\mathrm{n}=120 \\
\text { Freq. }(\%)\end{array}$ & $\chi^{2}$ & p-value \\
\hline \multicolumn{5}{|l|}{ Weight for Age } \\
\hline Overweight & $2(1.6)$ & $3(2.5)$ & 3.635 & 0.456 \\
\hline Normal & $100(78.7)$ & $93(77.5)$ & & \\
\hline Underweight & 17 (13.4) & $20(16.7)$ & & \\
\hline Severely underweight & $8(6.3)$ & $4(3.3)$ & & \\
\hline \multicolumn{5}{|l|}{ Height for Age } \\
\hline Normal & $32(25.2)$ & $43(35.80)$ & 8.576 & 0.035 \\
\hline Stunted & $55(43.3)$ & $57(47.5)$ & & \\
\hline Severely stunted & $40(30.5)$ & $20(16.7)$ & & \\
\hline \multicolumn{5}{|l|}{ Weight for Age } \\
\hline Above normal & $6(4.7)$ & $18(15.0)$ & 12.668 & 0.013 \\
\hline Normal & $117(92.1)$ & $101(84.2)$ & & \\
\hline Wasted & $4(3.1)$ & $1(0.8)$ & & \\
\hline
\end{tabular}

\section{Discussion}

The ability of the pupils to enjoy and like the food served in a SFP is vital because it ensures that they eat and finish the meals to enable them gain the maximum nutrients from the meal. Findings from the study showed that although most of the children liked the food, a few of them (13.4\%) were not satisfied with it because it was either spicy or too little or that the meal was made from a food item they didn't like. Studies on the perception of parents and their children regarding SFP also showed that their perception affected whether or not their children ate the food and therefore had an effect on their nutritional statuses. ${ }^{13,14}$

Most of the pupils in both schools usually ate breakfast before coming to school. This good nutritional practice has been shown to have a positive effect on improving intellectual capacity, providing needed nutrients and helping the children to maintain a good nutritional status. ${ }^{14,15}$ There was no statistically significant difference in the frequency of eating breakfast or dinner by the pupils on the SFP and those not on SFP. However, the proportion of pupils who ate breakfast was higher in the SFP group than those in the non-SFP group. This could explain why their nutritional status was nearer normal than those not on the SFP. This high level of good dietary practices of both groups of pupils may explain why their level of malnutrition was so low, compared with national levels.

The statistical difference in the nutritional status between the two groups is important as it suggests that those who were fed in school had lower levels of both stunting and obesity than those who were not on SFP. This therefore shows the critical nutritional role that the SFP plays in their well-being. Other researchers also found that undernutrition, stunting in particular, was more common in pupils from schools not on SFP, when compared with their peers from schools with SFP. ${ }^{16,17}$ This suggests that in the long term, the school feeding programme will improve the nutritional status of school aged children in Nigeria if properly implemented and 
sustained. This is of public health importance because the commonest nutritional problem in Nigerian children, is stunting and if the SFP can tackle it appropriately, the national nutritional indicators will improve with time. ${ }^{7}$

\section{Conclusion}

The pupils on SFP had a good perception about the foods served. They also had better dietary practices as well as maintained healthier nutritional status than their counterparts not on SFP in public schools. It is therefore recommended that nutrition education should be taught to all school aged children in public schools as a means of enhancing their acceptability of meals served. Nutritional assessment of school aged children should routinely be taken; whether they are on a SFP or not. The Plateau state government should scale-up the introduction and sustenance of the School Feeding programme, as well as improve the quality and quantity of the meals served, in order for the objectives of the programme to be met.

\section{References}

1. Agbozo F, Atitto P, Abubakar A. Nutritional status of pupils attending public schools with and without school feeding program in Hohoe Municipality, Ghana. Journal of Food and Nutrition. 2017;5(7):467-474.

2. United Nations Children Fund.

Nutrition's lifelong impact. Accessed $5 / 5 / 2019$. Available from:

https://www.unicef.org/nutrition/inde x_lifelong-impact.html

3. Falade OS, Otemuyiwa I, Oluwasola O, Oladipo W, Adewusi SA. School feeding programme in Nigeria: The nutritional status of pupils in a public primary school in Ile-Ife, Osun State, Nigeria. Journal of Food Nutrition Science. 2012;3(1):596 - 605.

4. Bain LE, Awah PK, Geraldine N,
Kindong NP, Sigal Y, Bernard N, et al. Malnutrition in sub-Saharan Africa; burden, causes and prospects. Pan African Medical Journal. 2013;15(1): 120.

5. Manyike PC, Chinawa JM, Ubesie A, Obu HA, Odetunde OI, Chinawa AT. Prevalence of malnutrition among pre-school children in SouthEast Nigeria. Italian Journal of Paediatrics. 2014;40:75.

6. Monyeki MA, Awotidebe A, Strydom GL, Ridder JH. The challenges of underweight and overweight in South African children: Are we winning or losing the battle? A systematic review. International Journal of Environmental and Respiratory Public Health. 2015;12(2):1156 1173.

7. National Nutrition and Health Survey. Nigeria; 2015. Accessed 12/11/2019. Available from https://somlpforr.org.ng/pdfs/smartre sults.

8. Elementary School Feeding and Health Programme Transition Strategy: State of Osun, Nigeria. Accessed 12/11/2019. Available from https://hgsf-global.org/.../252elementary-school-feeding-andhealth-programme-tran.

9. Yendaw E, Dayour F. Effect of the national school feeding programme on pupils enrolment, attendance and retention: A case study of Nyoglo of the Savelugu-Nantong Municipality. Ghanian Journal of Repository Medicine. 2015;5(3):431-353.

10. Kearney JE. A comparative analysis of the five different school feeding strategies in the Vaal region. Vaal University of Technology, South Africa. Accessed 19/02/2019

11. Uwameiye BE. Assessment of the impact of the UNICEF supported 
school feeding program on attendance of pupils in Federal Capital Territory. International Journal of Academic Research and Progress in Educational Development. 2013;2(1):209 - 218.

12. Plateau State Government. Plateau State: Local Government Areas. Accessed 18/05/2018. Available from http://www.plateaustate.gov.ng/page/ jos-north

13. Rocha NP, Filgueiras MS, Albuquerque FM et al. Analysis of the national school feeding program in the municipality of Viçosa, state of Minas Gerais. Rev SaudePublica. 2018;52:16. Dalma A

14. Kastorini CM, Zota D, Veloudaki A, Petralias A, Yannakoulia M et al.Perceptions of parents and children, participating in a schoolbased feeding programme in disadvantaged areas in Greece: a qualitative study. Child Care Health Dev.2016;42(2):267-277.

15. Rampersaud GC. Benefits of breakfast for children and adolescents: Update and recommendations for practitioners. American Journal of Lifestyle Medicine. 2009;3(2):86-103.doi:10.1177/15598 27608327219.

16. Spence C. Breakfast: The most important meal of the day? International Journal of Gastronomy and Food Science. 2017,8(1):1-6.

17. Kwabla MP, Gyan C ZotorF. Nutritional status of in-school children and its associated factors in Denkyembour District, Eastern Region, Ghana: comparing schools with feeding and non-school feeding policies. Nutrition Journal. 2018;17(1):8. doi: 10.1186/s12937018-0321-6. 